\title{
Analysis of the Role of Sport in the Management Textbook: A Study of Sports Images in Organizational Behavious Textbooks from 1992 to 2011
}

\author{
Heidi Weigand ${ }^{1}$ and Albert J. Mills ${ }^{2}$ \\ 1. Centre for the Study of Sport and Health, Saint Mary's University, Halifax, Nova Scotia B3H 3C3, Canada \\ 2. Department of Management, Sobey School of Business, Saint Mary’s University, Halifax, Nova Scotia B3H 3C3, Canada
}

\begin{abstract}
This paper examines a selection of OB (organizational behaviour) textbooks from 1992 to 2012. Using both content analysis and semiotic language analysis, the purpose of this paper is to illustrate how sports images in textbooks—although used to ostensibly explain organizational behaviour concepts—can have implications for addressing issues of gender, race, ethnicity, disabilities, and intersectionality. We conclude that sports images and metaphors (along with other asides, examples, and illustrations) need to be used carefully and reflectively.
\end{abstract}

Key words: Sport, intersectionality, images, organizational behaviour.

\section{Introduction}

Feminist analyses of educational materials have long argued that it is not only the main content but the asides that contribute to the gendered nature of those materials [1], for example, talking about the “embedded” nature of gendered (and racist) assumptions, argued that we need "to treat scientific writing not only as a source of information as defined by the author, but also as a text revealing something about the author”. She goes on to argue that to uncover the "underlying assumptions" of gender, race and ethnicity, we need to undertake a thorough examination of texts, not only in terms of their major arguments (which usually appear benign), but "in terms of their asides, illustrations and examples. Looking not at what authors thought needed explaining but what they thought did not- that is, their taken-for-granted assumptions” [1].

In North America (and parts of Europe), the management textbook exemplifies an important genre of scientific writing. It involves a style of writing

Corresponding author: Heidi Weigand, Ph.D. candidate, administrative director, research field: sport and health. E-mail: Heidi.Weigand@smu.ca. designed to convey information to business students. As such, management textbooks are one of the primary forms of knowledge dissemination that business students are exposed to. However, as a growing number of studies have indicated, the management textbook, as a genre, tends to draw on a particular narrative style [2] that is supported by the use of examples, illustrations, case studies, and, increasingly, photographic material. In the process, such works do not simply impart knowledge (i.e., information) but "knowledge" (i.e ways of thinking) [3] that shapes our ideas of history [4]; theories [5], practice [6] and theorists [7]; the relationship between organization and society [8]; and gender, race, ethnicity and class [9].

Drawing on the work of Reference [1] and recent studies of the role of the management textbook, we set out to analyze the use of photographic material in management textbooks, specifically the use of sporting images. We were drawn to the study of sports images for a number of reasons. First, more than almost anything else, photographic images draw on supposed social assumptions to make their point. Second, sports-especially professional sports-are 
increasingly rare among organizational bodies in being able to develop (and profit by) segregated teams (at least in terms of gender). Third, unlike business examples, vignettes, and case studies, the performance of sport's athletes provides an indirect and less obvious example of business practice or experience. Indeed, textbook authors cannot rely on a sporting image alone to make a point, they need to develop an appropriate narrative that links sports to management in the minds of the reader. What those narratives are and what the implications are for gender, race and management theory is the focus of this paper.

Utilizing a combination of content analysis and semiotics, we examine ten organizational textbooks published between 1992 to 2012 to understand (1) how sport is used to convey organizational behavior concepts such as motivation, teamwork, culture, leadership and stress in management textbooks, and (2) what, if any, are the implications for gender, race, ethnicity, disabilities and intersectionality in management.

\section{Materials and Methods}

\subsection{Theoretical Framework}

\subsubsection{Intersectionality Theory}

Over the past decade or so, the study of discrimination has seen an increasing number of researchers arguing for an intersectional approach that takes into account the often multiple forms of discrimination that people may face. For example, a black, immigrant woman may face the "triple jeopardy" of different forms of discrimination [10]. Reference [11], for example, refers to the need to take into account intersecting forms of discrimination, arguing that oppression cannot simply be reduced to one or other lived experience based on ethnicity, race, gender, and so on, but on combinations of such experience that work together to produce injustice. She calls this a focus of the intersectionality of discrimination, which she describes as an "analysis claiming that systems of race, social class, gender, sexuality, ethnicity, nation, and age form mutually constructing features of social organization”. Building on this approach, Reference [12] argues "it is important to recognize that different oppressions surface as more important from time to time.”

More recently, Reference [13] has described intersectionality as "the acknowledgement that the social differentiations of gender, race, disability, sexual orientation, religion or belief, and age do not create homogenous groups." She goes on to state that it "has now become clear that there is no longer, if ever, a uniform story of blanket disadvantage for any of these groups. Therefore, it is timely to acknowledge, confront, and deal with the actual problems of separate and relative deprivation, and sometimes conflicting experiences and interests, both between different categories of disadvantage and even within these categories themselves” [13].

Nonetheless, "despite the emergence of intersectionality as a major paradigm of research", there has been relatively little methodological consideration of how to study [14] or "operationalize" [13] intersectionality. Reference [14] attempts to deal with the methodological issues by outlining three approaches according to "their stance towards categories” (e.g., race, gender, and ethnicity). For example, a poststructuralist account to intersectionality focuses on "anticategorical complexity" by attempting to avoid fixed categories (such as black/white, male/female) etc., by deconstructing their use as a way of addressing discrimination. In the process, according to Reference [14], it fails to take into account issues of categorization as lived experience and the possibility of identity and voice in a research process that locates subjectivity in multiple identities/voices. A second form of approach is one that focuses on "intracategorical complexity" that "acknowledges the stable and even durable relationships that social categories represent at any given point" [14] and draws on broadly established notions of gender, race, ethnicity, and so on to "identify a previously invisible 

Organizational Behavious Textbooks from 1992 to 2011

group and reveal the complex nature of its members' daily lived experiences" [13]. The "primary subject of analysis is typically either a single social group at a neglected point of intersection of multiple master categories or a particular social setting or ideological construction, or both” [14]. A third approach and one that we take in this paper, focuses on "intersectional complexity" by using existing categories strategically. The starting point of this approach is that "there are relationships of inequality among already constituted social groups, as imperfect and as ever changing as they are, and it takes these relationships as the center of analysis [14].

In drawing on an intersectional complexity approach to the study of race, disability, ethnicity and gender in textbooks, we are mindful of three levels of analysis. First, we look for the existence of the categories (e.g., images of race, gender, ethnicity) themselves in the textbooks, investigating if the textbooks examined serve to reinforce categories of people (e.g., is race stressed when discussing an individual) Second, we look at the extent to which existing categories become privileged or marginalized in selected settings. For example, are there instances where images of women are marginalized when compared to men but privileged where "white" women are compared to "non-white" women? Third, are there points where intersecting discriminations are produced?

\section{Methodological Framework}

Our theoretical starting point is postpostitivism[15], which draws from those traditions that share a common reaction to positivism in questioning "social reality and knowledge production from a more problematized vantage point, emphasizing the constructed nature of social reality, the constitutive role of language, and the value of research as critique" [15]. This theoretical perspective, in turn, shapes the researcher's choice of methods [16], including narrative analysis [17], semiotics [18], and content analysis [16].

We chose for our analysis ten organizational behaviour textbooks published in the past two decades, 1992-2012. The texts were chosen from a collection of over five hundred North American textbooks published between 1924 and $2012^{1}$. The selection was not designed to obtain a representative sample. The aim, rather, was to gain some understanding of the problems of using sporting images and metaphors in the teaching of management. We did, however, set out to gain some sense of how the use of sports images may be changing over time. For reasons of time and resources, we decided on a period of twenty years, in part to take account of the changing influence of the AACSB (Association to Advance Collegiate Schools of Business), whose 1993 rule-changes shifted attention towards diversity management (as well as globalization and information technology) that was subsequently reflected in management textbooks [19]. It was during this same period that Canadian business schools came under the influence of the AACSB and its accreditation criteria. Initially, the Canadian Federation of Business School Deans, meeting in 1994, rejected AACSB accreditation of Canadian Business Schools [20], but this rapidly changed and quickly saw a rapid rise in the number of Canadian business schools seeking and gaining AACSB accreditation [21].

The initial selection of texts started with 20

\footnotetext{
${ }^{1}$ The textbooks are part of a collection that were acquired from different sources that include solicited and unsolicited publisher copies, colleagues' discarded books, and a number that were purchased from second-hand book sellers. The collection-consisting of 507 North American textbooks-was developed for the study of textbook production over time and includes books from every decade from the 1920s to the present time. It is not claimed that the collection constitutes a representative sample but it does include a number of "best selling" works in the field and works published by some of the leading management educators of the time (including various presidents of the Academy of Management). The textbooks are drawn from the fields of Human Resources Management, Organizational Behaviour, Organization Theory, Management, and (Introduction to) Business. All the textbooks were written for undergraduate business students, with $87 \%$ (462) published in the United States and the remaining $13 \%$ (67) were published in Canada. Research using this collection has generated several published studies in such journals as Human Relations, Group \& Organization Management, Management \& Organizational History, and the Journal of Management History.
} 
Organizational Behavious Textbooks from 1992 to 2011

textbooks (10 Canadian and 10 United States) for a project focused on comparisons of Canadian and United States business textbooks: a study that is still on-going. However, in the course of this project, another study began to emerge from our analysis of the photographs that peppered the books we were reviewing. In the process, we shifted gears and decided to focus of the role of sports images in the North American textbook. To that end, and following a technique adopted elsewhere [6, 22], we filtered our focus down to the first ten textbooks we had already begun to analyze. These textbooks contained a total of 937 pictures, including 51 representing sport (Table 1). The sample includes six Canadian textbooks and four from the United States, however, we did not note any substantial difference based on nation. In order to focus on the outcome of the texts rather than the authors, we have kept the names of the texts anonymous, and labeled them 1-10. This is to encourage discussion about the use of sporting and other illustrations rather than as a critique of well-intentioned authors.

The pictures are analyzed using a combination of content analysis and semiotic language analysis to draw out the subtle themes in the pictures. With the emergence of a central theme of race, gender and ethnicity in the pictures, we were drawn to intersectionality theory [13] to understand the multiple dimensions of discrimination. We also draw in intersectionality theory to analyze how these images influence the power networks in organizational concepts in the management textbooks used in the case study.

\subsection{Content Analysis}

Content analysis is a tool used by both qualitative and quantitative processes to help filter the data into manageable portions for analysis. In qualitative research, content analysis is a method used to determine the presence and meaning of concepts, terms, or words in one or more pieces of recorded communication [15]. This systematic and replicable technique allows for compressing many words of text into fewer content categories based on explicit rules of coding in order to allow researchers to make inferences

Table 1 Gender, Race and Physical/Mental Ability depicted in Selected Textbook.

\begin{tabular}{|c|c|c|c|c|c|c|c|c|c|c|c|}
\hline Textbook \# & $\begin{array}{l}\text { Total } \\
\text { pictures }\end{array}$ & $\begin{array}{l}\text { Number } \\
\text { of sports } \\
\text { pictures }^{1}\end{array}$ & $\begin{array}{l}\text { Percentage } \\
\text { of pictures } \\
(\%)\end{array}$ & $\begin{array}{l}\text { Images of } \\
\text { White } \\
\text { woman }\end{array}$ & $\begin{array}{l}\text { White } \\
\text { man }\end{array}$ & $\begin{array}{l}\text { Mixed } \\
\text { group }^{2}\end{array}$ & $\begin{array}{l}\text { "Non-White" } \\
\text { ethnic woman }\end{array}$ & $\begin{array}{l}\text { “Non-White” } \\
\text { ethnic man }\end{array}$ & $\begin{array}{l}\text { Black } \\
\text { man }\end{array}$ & $\begin{array}{l}\text { Black } \\
\text { woman }\end{array}$ & $\begin{array}{l}\text { Persons } \\
\text { with } \\
\text { disability }\end{array}$ \\
\hline 1 & 65 & 7 & 11 & 1 & 10 & 1 & 1 & 0 & 0 & 0 & 0 \\
\hline 2 & 108 & 8 & 7 & 6 & 8 & 1 & 0 & 0 & 6 & 0 & 0 \\
\hline 3 & 97 & 7 & 7 & 2 & 11 & 0 & 0 & 0 & 2 & 0 & 0 \\
\hline 4 & 105 & 4 & 4 & 2 & 3 & 1 & 1 & 0 & 0 & 0 & 0 \\
\hline 5 & 102 & 5 & 5 & 21 & 5 & 2 & 0 & 0 & 0 & 0 & 0 \\
\hline 6 & 84 & 3 & 4 & 0 & 4 & 1 & 0 & 0 & 0 & 0 & 0 \\
\hline 7 & 57 & 3 & 5 & 10 & 2 & 0 & 0 & 0 & 1 & 2 & 0 \\
\hline 8 & 156 & 8 & 5 & 2 & 14 & 0 & 0 & 2 & 3 & 0 & 0 \\
\hline 9 & 103 & 4 & 4 & 1 & 5 & 1 & 0 & 0 & 1 & 0 & 0 \\
\hline 10 & 60 & 2 & 3 & 4 & 4 & 0 & 0 & 0 & 0 & 0 & 0 \\
\hline Total & 93737 & 51 & 5 & 49 & 66 & 7 & 2 & 2 & 13 & 2 & 0 \\
\hline $\begin{array}{l}\text { Percentage } \\
\text { of pictures } \\
(\%)\end{array}$ & & $5^{3}$ & & $35^{4}$ & $47^{4}$ & $5^{4}$ & $1^{4}$ & $1^{4}$ & & $1^{4}$ & 0 \\
\hline
\end{tabular}

${ }^{1}$ There can be multiple members in the pictures so the total members separated by categories will not equal the number of pictures

${ }^{2}$ This refers to photographs composed of fairly large groups of men and women where it was difficult to determine the gender, race or ethnicity of the people depicted.

${ }^{3}$ This is a calculation based on the number of sports images as a percentage of the total images in the ten (10) textbooks.

${ }^{4}$ The remaining column totals are based on the number of persons representing the category divided by the people total number of people in all the sports images (141). 

Organizational Behavious Textbooks from 1992 to 2011

about the author (individuals, groups, organizations, or institutions), the audience, their culture and time [23, 24]. A recent study [25] found that content analysis was a method in use by researchers across seven of the twenty divisions of the ASAC (Administrative Sciences Association of Canada).

Our initial use of content analysis was to gain information on the type and extent to which sports images were used across the ten textbooks, and to ascertain what forms of gender and racial identities were evident (Table 1). This was problematic on at least two counts. First, in order to study the extent to which forms of discrimination were evident we had to resort to broad stereotypical names, e.g., "white" woman, "black" man. Second, although we were helped by the fact that many of the sports figures depicted are well known, we have to concede that perceptual biases will likely have influenced our decisions as to who "appears" to be "white", "black" or other "non-white" ethnic persons. Nonetheless, we would contend that we are trying to reflect (how the pictures were being presented) rather than describe (the people imaged).

We then used content analysis to detail the types and occurrence of the sports depicted and then looked for any occurring themes that arose out of the numerous accounts used to discuss and image those sports and their relationship to organizational behaviour concepts.

\subsection{Semiotic Analysis}

Semiotic analysis is a method of analyzing signs (e.g. words and images) to reduce non-numeric data to their component parts without losing essential meanings [15]. According to Reference [18], "semiotics is primarily a mode of analysis that seeks to understand how signs perform or convey meaning in text”. This method of semiotic analyses comprises first definition reduction and second identification of interrelationships [26]. Photographs seem to be prototype of visual messages, which are (assumed to be) true because they fulfil the semantic criterion of correspondence to the facts. Under certain circumstances, photographs are even recognized by the courts as documentary evidence, which may replace evidence by ocular inspection or by verbal testimony [27].

Organizational research has long taken an interest in visual documents as part of the data collection process, including photographs, videos, artwork, symbols that all help to convey the image and identity of the company. Examples of this type of approach include a study of the annual reports of GM (General Motors) over time to analyze the depiction of men, women and people of colour [28]; and a study of the depiction of gender in the annual reports of a number of European companies [29].

\section{Findings}

In this section, we look at the individual elements of gender, race and ability first and then the intersection of multiple dimensions in analysis of the selected textbooks.

\subsection{Men and Women of the Corporation ${ }^{2}$}

Level 1: Representation of women as the Minority: The first thing we noted in the texts was that the sporting images included many more males than females. In overall terms, counting the number of clearly visible and distinguishable individuals, just under $60 \%$ of the images were of men and just under $40 \%$ were of women (Table 1). However, this does not take into account the focus of the picture nor the fact that two cases of women's teams account for $59 \%$ of all female images; 1 involved 20 members of the Canadian women's hockey team and another involved 9 members of an American basketball team. On the men's side, while one picture featured nine members (13.5\%) of a male hockey team, the remaining images consisted of between 1 and 5 members each. In contrast, women were only central in 9 images (25\%), while

\footnotetext{
${ }^{2}$ Here we are using the title of Kanter's(1977) landmark study [30].
} 
men were central in 27 (75\%). A further 11 images included both males and females, $23 \%$ of the total number of images. However, we need to probe further to see how women were presented compared to men. There were also 4 images where it was impossible to determine the characteristics of the participants.

Level 2: Imaging Male and Female Characteristics: The female-only images are associated with goal setting, teamwork (3), expectancy theory (2), escalation of commitment, leadership, and fitness. The male-only images are associated with fitness, referent power (2), rules, equity theory (2), creative problem solving (2), leadership (3), motivation (5), teams (5), culture (2), compensation, innovation, person-job fit, and conflict and power. The images of men and women together are concerned with communication, fitness/wellness/spirituality (4), training, power and politics, motivation, culture, work-life balance, and teams.

At this surface level, we observe that men are more likely than women to be associated with leadership, power, and problem solving. A closer look at the respective accompanying texts indicates that male associations with these characteristics are much stronger than the relative numbers indicate. For example, one of the male-only references to culture speaks about "the strong sports-oriented culture instilled by its founder Philip Knight”; one team-oriented image focuses on the "challenge for Gretsky and Team Canada management”; an image on problem solving focuses on the leadership style of Bob Goodenow as "boss" of the National Hockey League Players Association; two images with motivation-oriented stories talk about male leaders, including the leadership of cyclist Lance Armstrong who "had to inspire and motivate his team members to do their best”, and the leadership of B.C. Lions head coach, Wally Buono who "is not afraid to make tough decisions"; an image on innovation focuses on two men who built a successful company; and, finally, the story on conflict and power features National Hockey
League Gary Bettman and his power to lockout the players to force a settlement .

In contrast to men, women are only referenced in leadership positions on two occasions. A direct reference to leadership; discussing the "employee-oriented" leadership style of CEO Sally Jewell, a story about executive compensation that shows a man holding a picture of a yacht, while the text discusses the resignation of Eleanor Clitheroe, the CEO of Hydro One that "many people felt her compensation in particular was far too much for a public sector organization”. In terms of power, while men are portrayed in several stories as having power, there are no references to women exercising power. A good example is the contrasting stories on conflict and power. In the male-only image, Gary Bettman is referred to as exercising power while the only reference to power and conflict that includes women casts the woman and her male skating partner as the victims of the exercise of power. A similar interesting contrast is on the discussion of teams. Female teams are described in terms of being supportive, dedicated, well trained, and high-performance. Male teams are described as effective, excelling, victorious, proud, dedicated, trusting, cohesive, and goal accomplishing. There are some similarities in terms of dedication but differences are presented in terms of effectiveness (men) and supportive (women). Overall, images of men were more action oriented, and encouraged the reader to identify with either the overt or embedded voice of the male leader. Images of women were, with one exception, either focussed on individual achievement (e.g., the individual athlete) or leaderless achievements (e.g., women engaged in a yoga exercise). Even where men are pictured as individual athletes there is often reference to their leadership or example to fellow athletes. For example, basketball player Michael Jordon is described as having referent power, while golfer Lorie Kane is only discussed in terms of her motivation.

Talking about men and women: Allowing for the 

Organizational Behavious Textbooks from 1992 to 2011

much great number of male-only images, the descriptors associated with males greatly outnumber those associated with females (Fig. 1). Analysis of the descriptors shows a very similar trend to the discussion of leadership, power, etc., in the previous section. Men are much more likely to be described as a leader, manager or boss, task-oriented, physically and mentally tough, powerful, and driven to win. While women are talked about in terms of their efforts to succeed, they are more imaged as supportive than leading.

\subsection{Normalizing Able-bodiedness and Whiteness}

4.2.1 Level 1: Representations of Able-bodiedness and Whiteness

As is clear from Table 1, the sporting images are overwhelmingly focused on "white", able bodied, men-of the people imaged just under 60\% are men, almost 86\% appear "white” and 100\% are able bodied. This is one of the dangers of using sporting images and metaphors in an area of endeavour where the most popular sports (in terms of media attention) are those played by able bodied men: women's sports and events such as the Special Olympics receive far less media attention. Less explicable is the relative absence of people of colour given their presence in the mainstream North American sports of football, baseball, and basketball (but not hockey) ${ }^{3}$.

\subsubsection{Level 2a: Imaging the Disabled}

By focussing on sporting events, especially selected mainstream sports, only the able bodied are associated with the world of work and its management. In the absence of those with mental and/or physical disabilities, the sports images may serve (unintentionally) to reinforce the privileging of a sense of able-bodiedness. Several images focus on company fitness and wellness programs - in all cases lauding a sense of physical (e.g., images of exercises), and mental health (e.g., images of yoga programs). In

\footnotetext{
${ }^{3}$ The various references to hockey in the Canadian textbooks may be one explanation.
}

addition, most other images stressed success through some kind of athletic ability, with focuses on the application of physical and mental strength.

\subsubsection{Level 2b: Imaging "Whiteness”}

The overwhelming imaging of people with a "white" appearance serves to normalize "whiteness" [31, 32]. Linking “whiteness” with sporting narratives can also (inadvertently) link certain qualities (e.g., leadership, problem-solving) to management and whiteness. For instance, where women were imaged in the photographs the great majority featured white women-reinforcing associations between selected sports and whiteness. Of the non-white women imaged, one is a skateboarder who appears on a poster to advertise the 2010 winter Olympic games in Vancouver. The poster, rather than the woman imaged, is the focus of the story. So we learn nothing particular about her qualities, compared to those of the other “white” women imaged (Fig. 1). Another non-white woman appears as part of an acrobatic act that is referred to as risk taking. Finally, two black women are part of a group of 11 basketball players, described as "watching" and "supporting" their team members. With the exception of risk taking, only the white women are associated with active participation and leadership. We would repeat here that we are not referring to whiteness, blackness, and non-whiteness as inherent qualities of people but rather socially constructed through a variety of processes, including photographic imagery. Thus, although the pictures under study do not discuss the whiteness or ethnicity of the people imaged, they may marginalize those categories of women who are not imaged.

The issue of race is raised more so in relationship to men and may serve to compound the relative absence of black and other "non-white” women. Black men only appear 13 (9\%) times in a total of 7 pictures. In none of the pictures are black men imaged as leaders. Indeed in one of the pictures, a white coach who is the focus of the story is talking to two black basketball players. We learn nothing of the characteristics of the 


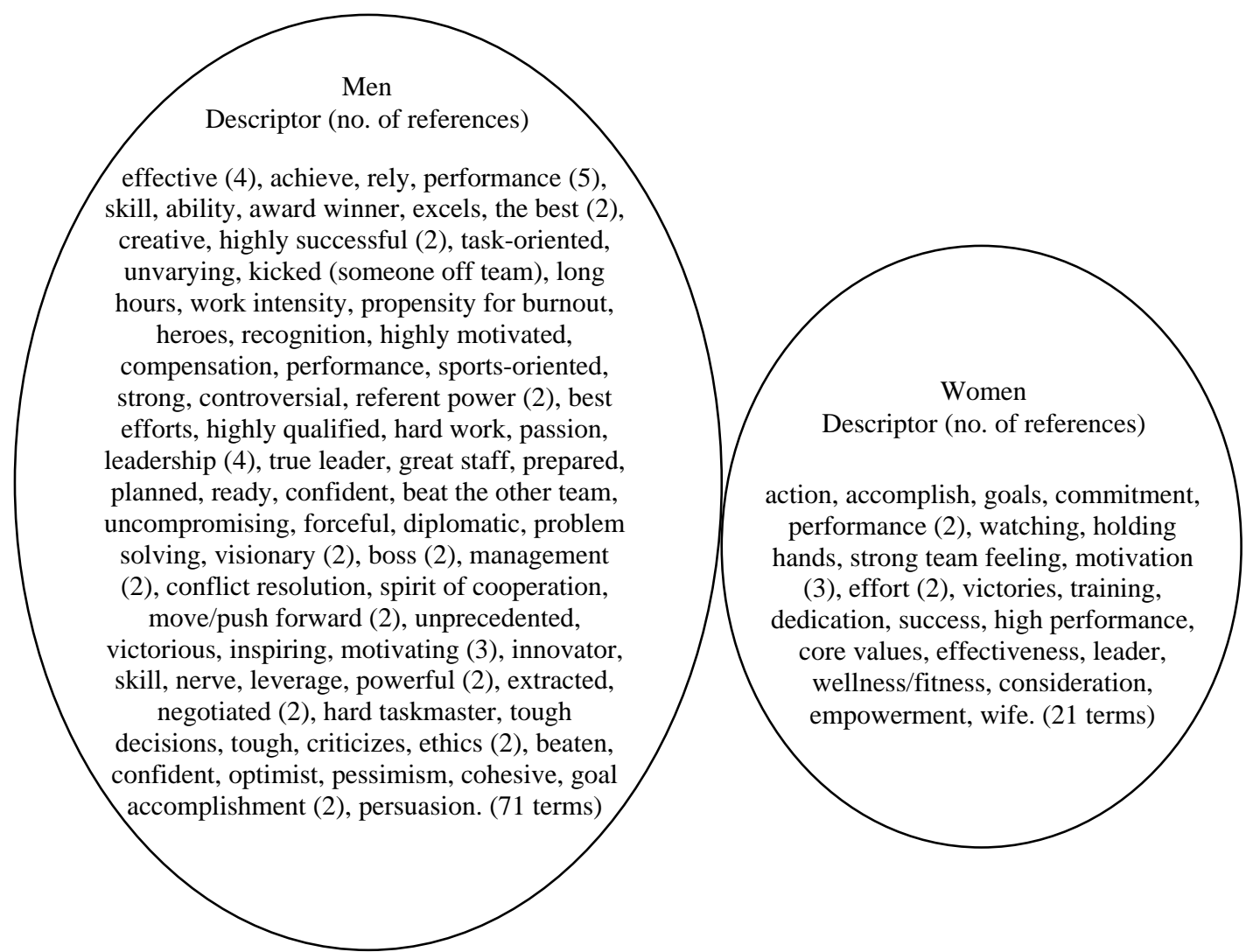

Fig. 1 Descriptors associated with men and women.

two players. Five other pictures focus on player performance, four on individual performance and one on team performance focussed on shared experience. One of the individual cases does refer to the referent power of the athlete (Michael Jordon) due to his performance. Another speaks directly to the efforts of baseball star Jackie Robinson to overcome racism. The final case is a group of men that include at least one black man as well as another "non-white" man and two or three white men that are characterized as creative problem solvers. Beyond images of black men, the other picture that includes a "non-white" man depicts him undergoing training as a sales clerk by engaging in hula-hooping activity.

Even in comparison to a focus on teams, people of colour are rarely discussed as part of teams; and in the only two cases they are part of a "shared experience" (men) or are "watching" and "supportive" (see above). White men are more likely to be discussed as team players and their qualities of effectiveness, efficiency, and having a winning character are discussed at greater length.

\subsection{Intersectionality}

In setting out to explore intersectionality, we examined the contrasts between areas of privilege and marginality as well as what is potentially compounded (e.g., being marginalized for disability, being a woman and being black), and what is mitigated (e.g., a black man who is unfavourable contrasted with a white man but favourably contrasted with a black woman).

In the textbooks analysis, men, whiteness, and able-bodiedness were privileged over all women, black men, people with disabilities, and visible minorities other than blacks. In the context of the textbooks' overall sporting images, whiteness and able-bodiedness were inseparable in their privilege. So the various texts served to create a situation where the combination of these two categories (whiteness, able-bodied) compounded a position of privilege. 
Being black and able-bodied was a mitigating effect. While black men contrasted unfavourably with white men in terms of leadership and team building qualities, the lauding of their performance drew attention to the excellence of their physical and mental attributes. The disabled, on the other hand, although directly missing from the various images were referenced indirectly through various discussions of the need for physical and mental fitness, and the avoidance of burnout and stress. In contrast with white women, black men fared slightly better on referent power, but women were perceived more capable of leadership. Black men were shown as having less positive characteristics than white women (except in the case where the woman appeared as the wife of an athlete).

White women fared less well against white men but appeared more capable than black women (who only appeared as "supporters"). Although non-white women were associated with risk-taking, their almost total absence from sports images made their appearance marginal against all but black women.

Ethnic origin associated with the category of visible minorities [33] was too marginal (only two women and two men were shown in any of the pictures) and too broad a category to make sense of in the textbooks. All four non-white people appeared to be from different ethnic origins. What we can say is that at any level of categorization these people were almost totally marginalized.

\section{Conclusion}

We began this paper by reviving a twenty-five year old feminist debate about the problematic use of examples, asides, illustrations and pictures in textbooks. Their unreflective use has tended to compound the problem of the neglect of race, gender, ethnicity and disabilities in the North American textbook since its inception [9], and the almost total ignorance of feminist organizational theory over the past forty years [34, 35].

The use of sporting images in management textbooks is an increasing feature and is likely related to the increasing demand by publishers for a greater use of photographic material. On the surface, the use of sporting images and metaphors in organizational behaviour textbooks makes good sense. As the photographs we reviewed make clear, sports are quite comparable to management, with commonalities that include goal setting, problem solving, leadership, team building, communication, motivation and a number of other related concepts. However, as we have attempted to show, these terms are not simply interchangeable and rely on context, a context that may be more or less problematic. For example, professional sports involve a powerful narrative of winning and losing. We have seen some of that in our discussion above (Fig. 1) where teams are described as being badly beaten or being victorious over another team. Too often mainstream male sports also focus on being tough, making hard decisions, kicking people off the team, etc. Thus, it is not so easy to translate one context of motivation (sports) into another (management) without the baggage of the former's narrative. Another powerful example is the issue of teams. In the context of professional sports, this typically means forming into a powerful unit to defeat other competitive teams, and to gain levels of effectiveness and efficiency in doing so. However, other researchers have shown the notion of teams is highly contextual and can refer to a dedicated group of caring professions whose coordination is the key to helping (rather than defeating) others [36]. Elsewhere other feminist analyses have also made the point about the problem of transferring concepts from one context to another [37].

Another problem with the use of sports, especially professional sports is that (1) this tends to exclude events for disabled athletes (e.g., the Special Olympics), and (2) reproduces segregated social activities. The former strengthens the focus on the able-bodied while the latter strengthens the idea that women are less capable across a range of activities and characteristics than are men.

A focus on some sports, such as ice hockey can have 

Organizational Behavious Textbooks from 1992 to 2011

the effect of reducing images of diversity, with so few black players in the National Hockey League. A focus on selected mainstream North American sports, such as baseball, basketball and football can open up the prospect of greater numbers of images of black and other "non-white" athletes, but the danger is that it can also reduce the potential to show people of colour across a range of activities involving power and leadership. With few exceptions, this is also true for women, who are more likely to be excluded across images of football and baseball and, to a slightly lesser extent, basketball.

It is perhaps ironic that only one of the images we studied actually mentioned discrimination (i.e., the story of Jackie Robinson) and none were used to discuss discrimination and/or diversity at work (the Jackie Robinson story was ultimately about motivation and suggests that discrimination has been dealt with in baseball). Arguably, there is great scope to do so by examining many of the issues we have raised so far.

In conclusion, we would not argue against the use of sports images and metaphors as organizational behaviour illustrations, examples, etc. However, we contend that they need to be used more reflectively than they have been to date. The selection of sports should be considered. Using images from the Special Olympics, for example, would be an interesting challenge for the author(s) to think through and relate to appropriate organizational behaviour and management concepts. Another challenge would be to try to reflect images of varying levels of sport (professional and amateur) to provide readers with images they can identify with their own direct experience. And every attempt should be made to ensure that the sports chosen and the focus of the images, allow for greater diversity at all levels. Finally, sports imagery could also be used to deal with diversity and discrimination at work, focusing not simply on the performances of those involved but their struggles for recognition. For example, the stripping of Mohammed Ali's world boxing title for his refusal to support the
Vietnamese War; the problems faced by Jim Thorpe and other indigenous athletes who reached the pinnacle of sporting fame only to end up in poverty and neglect; and a myriad of efforts by girls to overcome barriers to playing sports with boys.

\section{References}

[1] Reinharz, S. 1988. "Feminist Distrust: Problems of Context and Content in Sociological Work.” In The Self in Social Inquiry, edited by Berg, D. N., and Smith, K. K. Newbury Park, CA: Sage, 153-72.

[2] Czarniawska, B., and Gagliardi, P. eds. 2003. Narratives We Organize By. Amsterdam: John Benjamins Publishing Company.

[3] Foucault, M. 1973. The Order of Things; an Archaeology of the Human Sciences. New York: Vintage Books.

[4] Cummings, S., and Bridgman, T. 2011. "The Relevant Past: Why the History of Management Should Be Critical for Our Future.” Academy of Management Learning \& Education 10 (1): 77-93.

[5] McQuarrie, F. A. E. 2005. "How the Past Is Present(ed): A Comparison of Information on the Hawthorne Studies in Canadian Management and Organizational Behaviour Textbooks." Canadian Journal of Administrative Sciences 22 (3): 230-42.

[6] Cunningham, P. 2003. "The Textbooks of Philip Kotler: Their Role in Defining Marketing Thought and Practice.” Academy of Marketing Science 31 (2): 201-8.

[7] Dye, K. E., Mills, A. J., and Weatherbee, T. G. 2005. "Maslow: Man Interrupted-Reading Management Theory in Context." Management Decision 43 (10): 1375-95.

[8] Chanlat, J. F. 1996. "From Cultural Imperialism to Independence: Francophone Resistance to Anglo-American Definitions of Management Knowledge in Quebec.” In The Politics of Management Knowledge, edited by Clegg, S. R. and Palmer, G. London: Sage, 121-40.

[9] Mills, A. J., and Helms Hatfield, J. C. 1998. "From Imperalism to Globalization: Internationalization and the Management Text.” In Global Management: Universal Theories and Local Realities, edited by Clegg, S. R., Ibarra, E. and Bueno, L. Thousand Oaks, CA: Sage, 37-67.

[10] Mighty, E. J. 1997. "Triple Jeopardy: Immigrant Women of Color in the Labor Force." In Managing the Organizational Melting Pot. Dilemmas of Workplace Diversity, edited by Prasad, P., Mills, A. J., Elmes, M. and Prasad, A. Thousand Oaks, CA: Sage, 312-39.

[11] Collins, P. H. 2000. Black Feminist Thought: Knowledge, Consciousness, and the Politics of Empowerment (2nd ed.). 

Organizational Behavious Textbooks from 1992 to 2011

New York: Routledge.

[12] Bagilhole, B. 2006. "Exploration Of UK Equal Opportunities and Diversity Legislation and Implementation Agencies Through the Lens Of Intersectionality.” Presented at the European Conference on Equal Opportunities, University of Antwerp.

[13] Bagilhole, B. 2010. "Applying the Lens of Intersectionality to UK Equal Opportunities and Diversity Policies.” Canadian Journal of Administrative Science 27 (3): 263-71.

[14] McCall, L. 2005. "The Complexity of Intersectionality.” Signs 30 (1): 1771-800.

[15] Prasad, P. 2005. Crafting Qualitative Research. Working in the Postpositivist Traditions. Armonk, NY: M. E. Sharpe.

[16] Bryman, A., Bell, E., Mills, A. J., and Yue, A. R. 2011. Business Research Methods. First Canadian Edition. Toronto: Oxford University Press.

[17] Czarniawska-Joerges, B. 1997. Narrating the Organization: Dramas of Institutional Identity. Chicago: University of Chicago Press.

[18] Manning, P. K. 1987. Semiotics and Fieldwork. London: Sage Publications.

[19] Mills, A. J., and Mills, J. H. 2005. Reading Organization Theory: A Critical Approach to the Study of Organizational Behaviour and Structure. Aurora, Ont.: Garamond Press.

[20] Coleman, D. F., Wright, P. C., and Tolliver, J. M. 1994. "American-style Accreditation and Its Application in Canada: Perceptions of Utility.” Revue Canadienne des Sciences de l'Administration 11 (2): 192.

[21] McKee, M., Mills, A. J., and Weatherbee, T. G. 2005. "Institutional Field of Dreams: Exploring the AACSB and the New Legitimacy of Canadian Business Schools.” Canadian Journal of Administrative Sciences 22 (4): 288-301.

[22] Cummings, S., and Bridgman, T. 2008. Strawman: The Reconfiguration of Max Weber in Management Textbooks and Why it Matters. In Best Paper Proceedings of the Academy of Management Annual Meeting, Anaheim.

[23] Das, H., and Das, M. 2009. Gender Stereotyping in Contemporary Indian Magazine Fiction. Asian Studies Review 33 (March): 63-82.

[24] Helms Mills, J. 2003. Making Sense of Organizational Change. London: Routledge.
[25] Hartt, C. M., Yue, A. R., Helms Mills, J., and Mills, A. J. 2009. Method and Disciplinary Convention in the Administrative Sciences Association of Canada, 1978-2008: Implications for Teaching and Research. In Proceedings of the annual conference of the Atlantic Schools of Business conference, Moncton, NB, Oct.

[26] Thiemann, F. C. 1979. Semiotic Analysis, Publisher NA.

[27] Oliver, R. 1974. The Evidence in Criminal Proceedings. Zurich: Schulthess. (in German)

[28] Tinker, T., and Newmark, M. 1987. "The Role of Annual Reports in Gender and Class Contradictions at General Motors: 1917-1976.” Accounting Organizations and Society 12 (1): 71-88.

[29] Benschop, Y., and Meihuizen, H. E. 2002. "Reporting Gender: Representations of Gender in Financial and Annual Reports.” In Gender, Identity and the Culture of Organizations, edited by Aaltio, I. and Mills, A. J. London: Routledge, 160-84.

[30] Kanter, R. M. 1977. Men and Women of the Corporation. New York: Basic Books.

[31] Acker, J. 2006. Inequality Regimes: Gender, Class and Race in Organizations. Gender \& Society 20 (4): 441-64.

[32] Glenn, E. N. 1999. "The Social Construction and Institutionalization of Gender and Race.” In Revisioning Gender, edited by Ferree, M. M., Lorber, J. and Hess, B. B. Thousand Oaks, CA: Sage, 3-43.

[33] Abella, R. S. 1984. Equity in Employment. A Royal Commission Report. Ottawa: Ministry of Supply and Services Canada.

[34] Mills, A. J. 2004. "Feminist Organizational Analysis and the Business Textbook.” In Management Knowledge and the New Employee, edited by Hodgson, D. E. and Carter, C. London: Ashgate, 30-48.

[35] Tancred-Sheriff, P., and Campbell, E. J. 1992. "Room for Women: A Case Study in the Sociology of Organizations.” In Gendering Organizational Analysis, edited by Mills, A. J. and Tancred, P. Newbury Park: Sage, 31-45.

[36] Armstrong, P., Armstrong, H., Choiniere, J., Mykhalovskiy, E., and White, J. 1997. Medical Alert: New Work Organizations in Health Care. Toronto: Garamond Press.

[37] Ball, K. 2004. “Gendering New Managerialism.” In Identity Politics at Work. Resisting Gender, Gendering Resistance, edited by Thomas, R., Mills, A. J. and Mills, J. H. London: Routledge, 85-104. 